\title{
Chinese steamed bread fortified with green banana flour
}

\author{
*Loong, C.Y.L. and Wong, C.Y.H. \\ Department of Food Science and Nutrition, Faculty of Applied Sciences, UCSI University KL Campus, No.1 \\ Jalan Menara Gading, UCSI Heights, Cheras, 56000 Kuala Lumpur, Wilayah Persekutuan Kuala Lumpur, \\ Malaysia.
}

\begin{abstract}
Article history:
Received: 23 February 2018

Received in revised form: 11 March 2018

Accepted: 13 March 2018

Available Online: 29 March 2018

\section{Keywords:}

Chinese steamed bread,

Green banana flour,

Texture,

Consumer acceptability
\end{abstract}

\section{DOI:}

https://doi.org/10.26656/fr.2017.2(4).058

\begin{abstract}
Incorporation of Green Banana Flour (BF) into Chinese steamed bread (CSB) may be a strategy to fortify the traditional CSB due to its health benefits. However, BF-incorporated foods in general, have poorer sensory properties affecting consumer acceptability. The aim of this study was to examine the adjustment of water content from the original formulation and addition of coffee flavour on physical properties and consumer acceptability of BFincorporated CSB. Wheat flour as control was substituted with $15 \%$ BF varied by addition of $30 \%$ water and coffee flavour. Physical analysis (colour, volume, spread ratio and texture) of CSB and hedonic test for appearance, aroma, flavour, overall acceptability and preference ranking of CSB were conducted. Results showed no significant differences ( $>0.05)$ in specific volume, springiness, and adhesiveness among samples. A significant increase $(p<0.05)$ in spread ratio and softness was noted in CSB with added water, possibly due to better hydration of gluten proteins and starch which led to increased viscous flow in the dough and softer texture. Incorporation of BF caused greyness in the CSB whilst addition of coffee flavour together with BF contributed a brown colour. Results of hedonic and ranking tests showed that BF-incorporated CSB with added Coffee was most liked for its aroma, flavour, texture and overall acceptability. BF-incorporated CSB with additional water was comparable to control in most aspects of consumer acceptability. This study showed that the addition of more water into BF- incorporated CSB formulation can improve its sensory properties whilst coffee flavour successfully masked the unappealing appearance of the BF-CSB, therefore, increasing consumer acceptability. Hence, with further improvements of CSB and food products incorporated with $\mathrm{BF}$, there is potential that such products can be introduced into the food industry successfully.
\end{abstract}

\section{Introduction}

Chinese steamed bread (CSB) also known as mantou, is a common and popular food in Asia which has been successfully commercialised as frozen CSB. Variations with fillings like kaya, peanut, lotus paste, red bean paste and vegetables added into CSB have been developed to adapt to the local palate preference. However, the basic steamed bread consists of elementary ingredients such refined wheat flour, water and commercial yeast. In view of consumers' interest in healthy foods (Lau et al., 2012), such common foods can be fortified with functional ingredients such as banana flour (BF) produced from unripe bananas which contain dietary fibre and indigestible fraction (Menezes et al., 2011; Tiboonbun et al., 2011; Bezerra et al., 2013; Almanza-Benitez et al., 2015). Food products such as bread (Juarez-Garcia et al., 2006), pasta (OvandoMartinez et al., 2009; Almanza-Benitez et al., 2015), noodles (Choo and Noor Aziah, 2010) and cookies (Agama-Acevedo et al., 2012) consisting of mixtures of flour and banana flour had been reported to have significantly higher resistant starch, total dietary fibre, insoluble dietary fibre in comparison to their control counterpart. In addition, the BF noodles and cookies were found to have lower glycaemic index (GI) and carbohydrate digestibility rate (Choo and Noor Aziah, 2010; Agama-Acevedo et al., 2012). The resistant starch in unripe banana flour was found to have significantly reduced hunger and increased satiation in a group of volunteers (Sarda et al., 2016). In another study on BF in steamed bread with the addition of gluten (Noor Aziah et al., 2012), higher concentrations of essential minerals such as magnesium, calcium, potassium and phosphorus 
were also reported in comparison to the control. Increased in antioxidant such as phenolic contents (Ovando-Martinez et al., 2009; Almanza-Benitez et al., 2015) were also reported in pasta incorporated with BF. Banana flour was also found to have potential as a fat replacer in sausages (Alves et al., 2016).

However, from the research reported (Ritthiruangdej et al., 2011; Agama-Acevedo et al., 2012; Mohammed Zafar et al., 2012; Jirukkakul, 2016), it can be seen that the major problem in foods produced using $\mathrm{BF}$ as a substitute for wheat flour or rice flour was that they had a darker colour compared to the control. Regardless of how the BF was prepared, whether rinsing or soaking in citric acid or sodium meta-bisulphite solution, the same increase in brownness was observed in different BF products such as noodles, cookies, rice papad, edible banana films and also in BF flours dried at various temperatures (Bezerra et al., 2013; Bakare et al., 2017; Kongolo et al., 2017). Other attributes which were affected included the appearance and texture of food. For example, BF incorporated doughnuts had an increase in brownness and roughness (Chong and Noor Aziah, 2008), BF incorporated CSB had lower volume and a lower elasticity, (Noor Aziah et al., 2012) and BF incorporated muffins had reduced volume and increased hardness.(Ng et al., 2012). These significant differences in appearance, colour, and texture may affect the overall acceptability of the many potential BF- food products, as evident in a study on bread produced with pre-treated banana flour (Bakare et al., 2017).

Consumer acceptability is a crucial aspect which will influence a new product's success in the market, especially with such high competition rate in the current food industry (Siró et al., 2008). Hence, in the product development of Chinese steamed bread using BF, it is important to ensure that various sensory properties are either maintained or improved to increase and ensure its consumer acceptability in the future market.

It can be postulated that one of the reasons for poor sensory properties in BF enriched product is insufficient water hydration due to the high level of total dietary fibre and total starch in unripe banana flour (da Mota et al., 2000; Noor Aziah et al., 2012) and hence the high waterholding capacity (WHC) of the flour (Noor Aziah et al., 2012; Pragati et al., 2014). In a study by Noor Aziah et al. (2012) on steamed bread enriched with BF, green BF and mixtures of wheat flour substituted with $30 \% \mathrm{BF}$ with added gluten had higher water holding capacity (WHC) compared to the control which only used wheat flour. It was explained that the higher number of hydroxyl groups found in the fibre structure allowed more interactions through hydrogen bonding (Noor
Aziah et al., 2012). In bread formation, gluten is formed through hydration of bread proteins gliadin and glutenin. These proteins are responsible to provide the viscoelastic properties of bread hence supporting its structure, preventing it from collapsing (Swanson, 2004). Besides, a significant amount of water will be absorbed by the increased starch for the gelatinization reaction. As the WHC of dough increases, the dietary fibres compete with gluten and starch for water in hydration hence causing the gluten structure to be incompletely formed as well as causing poor gelatinisation process (Zhou and Therdthai, 2007) and therefore affecting the sensory properties of CSB. In another study on steamed bread, it was also found that adequate water level in the dough is needed to achieve high quality steamed bread (Rubenthaler et al., 1990).

An earlier study on the incorporation of green BF in CSB was carried by substituting 5\%, $10 \%$ and $15 \%$ wheat flour with green BF. Results showed that substitution with $15 \%$ BF was promising with $50 \%$ increase in total dietary fibre but with drawbacks of poorer appearance, texture properties and lowered consumer acceptability (unpublished). Against this background, the aim of this study was to investigate the addition of extra water into CSB incorporated with $15 \%$ $\mathrm{BF}$ and the extent to which the addition of natural coffee flavour affect consumer acceptability of the nutritionally enhanced CSB by using hedonic and ranking tests.

\section{Materials and methods}

\subsection{Materials}

Unripe green banana, Pisang Abu (Musa acuminata) at stage 1 and 2 ripeness according to banana ripeness chart (Dadzie and Orchard, 1997) were purchased from a local fruit supplier (H. Kee Trading, Kuala Lumpur) and food grade citric acid was purchased from Bake with Yen Sdn. Bhd. (Selangor). Both materials were used for the preparation of $\mathrm{BF}$. The ingredients used for $\mathrm{CSB}$ were Hong Kong Pau Flour (Edible Foods Sdn. Bhd., Kuala Lumpur) which is a low protein wheat flour (WF), castor sugar (Central Sugars Refinery (CSR), Selangor), instant yeast (Kijang, Melaka), baking powder (Kijang, Melaka), shortening (Edible Foods Sdn. Bhd., Kuala Lumpur) and cappuccino coffee emulco (Edible Foods Sdn. Bhd., Kuala Lumpur).

\subsection{Preparation of Banana Flour (BF)}

BF was prepared manually according to procedures adapted from Rodríguez-Ambriz et al. (2008), Saifullah et al. (2009) and Wang et al. (2012) with modifications of slicing the bananas and soaking them in citric acid before oven drying. $3794 \mathrm{~g}$ of green bananas were peeled 
and the banana pulp obtained (1898 g) were cut into 2 $\mathrm{mm}$ slices with a knife and immediately soaked in the $0.5 \% \mathrm{w} / \mathrm{v}$ citric acid solution for 10 minutes to prevent enzymatic browning (Saifullah et al., 2009). After that, the banana slices were drained and arranged in a metal tray, then dried in a conventional oven (Memmert, Germany) at $50^{\circ} \mathrm{C}$ for 18 hours until brittle. Dried banana slices were blended using a blender (Moulimex, France). The amount of banana flour obtained was $655 \mathrm{~g}$, giving a yield of $34.2 \%$. The powder obtained was then sieved through a US $50(0.028 \mathrm{~mm})$ sieve. Care was taken to perform these steps without delay to prevent moisture from being reabsorbed by the dried bananas and vacuum packed and sealed in polypropylene plastic bags with a vacuum packager (DZQ400/500, China). The packed flours were then stored in a chiller at $6 \pm 2{ }^{\circ} \mathrm{C}$ until further usage.

\subsection{Preparation of Chinese Steamed Bread (CSB)}

CSB was prepared batch-wise in the Food Science Laboratory at UCSI University, Kuala Lumpur. Substitution of wheat flour (WF) with $15 \%$ BF was used and the formulations in the study were $15 \% \mathrm{BF}(\mathrm{BF} 100)$, $15 \%$ BF plus additional 30\% water (BF130), 15\% BF plus additional $30 \%$ water and coffee (BFCoffee), as shown in Table 1. All ingredients were weighed using a top-pan balance (Setra, USA) whereas water was measured using a $100 \mathrm{ml}$ measuring cylinder. Sugar was dissolved in warm water and yeast was added to the sugar mixture and stirred well manually by hand. The yeast mixture was then left standing at laboratory room temperature of $25^{\circ} \mathrm{C}$ for 1 minute to allow activation of the yeast. The wheat flour, banana flour, and baking powder were sieved and mixed in a mixing bowl. Yeast mixture was slowly added to the dry ingredients and mixed at low speed for 1 minute with a hand mixer (Pensonic, Malaysia). Shortening was added to the formed dough and kneaded until an elastic yet workable dough consistency was achieved. The dough was placed in a bowl covered with a damp cloth and allowed to rest for 40 minutes in a $40^{\circ} \mathrm{C}$ incubator (Memmert, Germany) as fermentation continues. The proofed dough was rekneaded and sheeted manually with a rolling pin. A wooden frame was used to ensure that the dough sheets were of consistent thickness, which is $3 \mathrm{~mm}$. The sheet was rolled and the ends of the cylindrical dough tube were cut off to ensure a consistent and even shape. $2 \mathrm{~cm}$ dough pieces were then measured and cut from the rolled dough tube using a knife. The dough pieces were then placed on a metal plate steamed for 20 minutes in a steamer. The CSB was cooled, kept in polypropylene containers and stored in a commercial freezer (Fisher and Paykel, Australia). When required, the frozen CSB were re-steamed for 10 minutes.

\begin{tabular}{lcccc} 
Table 1. Formulations & & \\
& & & \\
Ingredients & WF & BF 100 & BF130 & Coffee \\
\hline Wheat Flour $(\mathrm{g})$ & 125 & 106.25 & 106.25 & 106.25 \\
Banana Flour $(\mathrm{g})$ & 0 & 18.75 & 18.75 & 18.75 \\
Sugar $(\mathrm{g})$ & 18.75 & 18.75 & 18.75 & 18.75 \\
Instant yeast $(\mathrm{g})$ & 1.0 & 1.0 & 1.0 & 1.0 \\
Baking powder $(\mathrm{g})$ & 0.6 & 0.6 & 0.6 & 0.6 \\
Shortening $(\mathrm{g})$ & 1.88 & 1.88 & 1.88 & 1.88 \\
Water $(\mathrm{ml})$ & 52 & 52 & 67.6 & 62.6 \\
Coffee $(\mathrm{g})$ & - & - & - & 5.0 \\
\hline
\end{tabular}
${ }^{1}$ WF: Control, $100 \%$ Wheat flour only BF100: 85\% Wheat flour, 15\% Banana Flour and 100\% water
BF130: $85 \%$ Wheat flour, 15\% Banana Flour and 130\% water
Coffee: $85 \%$ Wheat flour, $15 \%$ Banana Flour, 130\% water and $2.5 \%$ coffee

\subsection{Physical analysis}

Samples were allowed to cool for 10 minutes before being tested. The colour of the CSB was measured using a colorimeter (HunterLab ColorFlex EZ) for Lightness (L* 0 black, 100 white), a* (+red, - green) and $b^{*}$ (+yellow, - blue) values which was calibrated using a white reference plate under standard daylight settings. The $L^{*} a * b *$ values were transformed to Hue angle and Chroma through a mathematical function (Jha, 2010). The specific volume of the CSB was determined using the solid displacement method (AACC, 2000) with modifications using mustard seeds instead of rape seeds (Prasad Rao et al., 2007; Lai 2009). The spread ratio of the CSB was calculated from measurements on width and height of CSB measured using Vernier callipers (Hoseney et al., 1979; Bourne, 2002). Texture parameters of hardness, cohesiveness, springiness, and adhesiveness of the CSB were measured under the Texture Profile Analysis mode using a texture analyser (Brookfield CT3), with $5 \mathrm{~g}$ trigger, $10 \mathrm{~mm}$ deformation and a speed of $2 \mathrm{~mm} / \mathrm{s}$ and probe used was TA-AACC 36 (AACC Spec Probe $36 \mathrm{~mm}$ ).

\subsection{Consumer acceptability}

A panel of 110 consumers, both male and female, were recruited through convenience sampling from students of a local private university. For each coded sample, consumers had to score their level of liking towards the sample on a 9-point hedonic scale. Sensory attributes which consumers evaluated included texture, flavour, appearance, aroma and overall acceptability. Consumers were also asked to rank their preference among all the samples tested. The CSB samples were presented to the consumers in a randomised complete block design where all the samples were assessed by 
consumers. The evaluation was conducted in sensory booths of food science laboratory of UCSI University, Malaysia

\subsection{Statistical analysis}

All the data obtained from the physical analysis and consumer acceptability tests were analysed using SPSS version 18. One way ANOVA and Tukey's post-hoc test was used to determine the significant difference between different formulations for physical analysis and consumer hedonic test of CSB. Friedman test was used to analyse the results of preference ranking. Significant differences for all analyses were indicated by $\mathrm{p}<0.05$.

\section{Results and discussion}

\subsection{Physical analysis}

The appearance of CSB made using the various formulations are shown in Figure 1 and the results of the physical analysis in Table 2. A good quality CSB is expected to be well rounded, have a smooth surface, symmetrical shape and a milky or milky white colour (Zhu, 2014). In terms of surface texture and shape, it can be seen that BF100 had rough, wrinkled surface and lower height in comparison to control WF, BF130, and BFCoffee. In the processing of CSB, kneading the dough allows the hydration and development of gluten to build a uniform structure (Haegens, 2006). The additional $30 \%$ water added in BF130 and BFCoffee

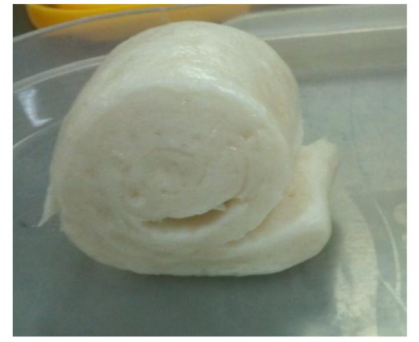

WF (Control) - 100\% WF $100 \%$ water

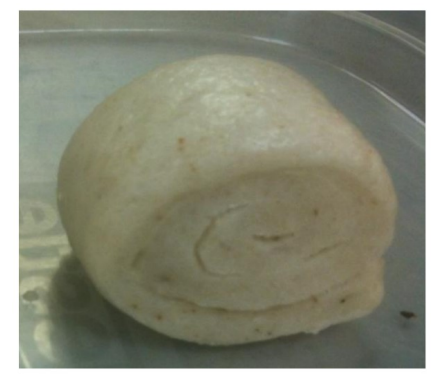

BF $130-15 \% \mathrm{BF}, 130 \%$ water

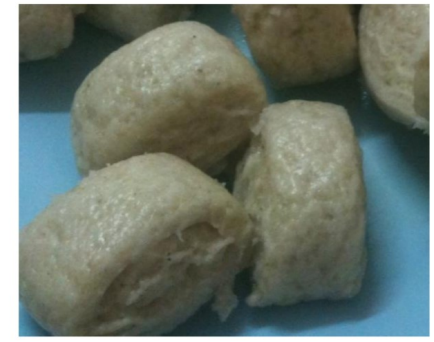

BF $100-15 \%$ BF, $100 \%$ water

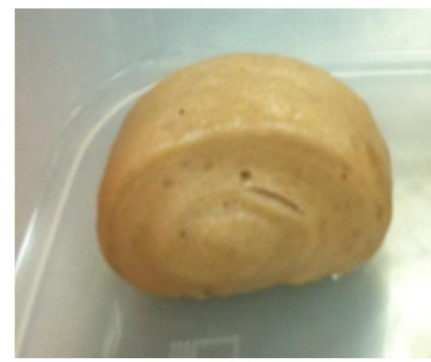

Coffee $-15 \%$ BF, $130 \%$ water, $2.5 \%$ coffee
Figure 1. Chinese steamed bread ${ }^{1}$ substituted with banana flour

1 WF: Control, 100\% Wheat flour only

BF100: 85\% Wheat flour, 15\% Banana Flour and 100\% water

BF130: $85 \%$ Wheat flour, 15\% Banana Flour and 130\% water

Coffee: $85 \%$ Wheat flour, 15\% Banana Flour, 130\% water and $2.5 \%$ coffee may have decreased the competition between gluten proteins for water enabling the improved development of gluten network leading to more elastic dough, better structure which can hold the gas during proofing and steaming of the bread (Gisslen, 2013).

In colour analysis, the $L^{*} a * b$ colour space was used. $L$ measures whiteness or darkness which ranges between 0 and 100 and $a$ value represents the redness and greenness (positive values are red and negative values are green) and $b$ value signifies yellowness and blueness (positive values are yellow and negative values are blue) (Ahmed et al., 2000; Jha 2010). WF was lightest in colour $\left(\mathrm{L}^{*} 81.38, \mathrm{a}^{*} 0.39, \mathrm{~b}^{*} 16.59\right)$ whilst BF100 had a significantly darker colour (L*70.82, a*1.93, b*15.70) $(\mathrm{P}<0.05)$ and visually seen with a grey hue and spots of banana seeds. The higher $a$ values in BF100 shows that it is further from green. Furthermore, the $b$ value shows that $\mathrm{BF}$ incorporated CSB was less yellow as compared to control WF. It can be seen that the incorporation of BF into CSB had caused the colour of CSB to darken with a grey hue. Similarly, BF130 exhibited grey hue in the bread. The significantly greyer colours of CSB incorporated with $\mathrm{BF}$ could be due to enzymatic browning during the processing of green bananas to $\mathrm{BF}$. According to Raju and Bawa (2006), enzymatic browning is the discolouration that results from oxidation of mono-phenolic compounds of plants in the presence of atmospheric oxygen and polyphenol oxidase (PPO). These compounds will be hydroxylated to odiphenols and further oxidised to o-quinones. It is very common for fruits like bananas that contain various enzymes, especially polyphenol oxidase (PPO) to be oxidised through enzymatic reactions as it contains various polyphenols (Raju and Bawa, 2006; Menezes et al., 2011). The darkening of BF incorporated CSB were evident despite treating with citric acid to reduce enzymatic browning similar to results of other studies on products substituted with BF (Tribess et al., 2009; Ritthiruangdej et al., 2011; Agama-Acevedo et al., 2012). The higher carbohydrate content in BF may have also resulted in an increase in Maillard reaction. Due to the natural brown colour of coffee, BFCoffee was the darkest among all the other CSB samples with the lowest $L$ value (52.58). Furthermore, it's $a$ and $b$ value were both 7.78, which indicated that it had more red and much less yellow respectively as compared to the rest. Although BFCoffee also contained BF, the common grey colour in the BF100 and BF130 was successfully masked by the darker brown colour of coffee with the CSB now appearing brown instead.

There was no difference in the specific volume of all the CSB samples. However, the spread ratio of BF130 and BFCoffee was significantly higher than WF and 
Table 2. Physical properties ${ }^{1}$ of CSB substituted with BF

\begin{tabular}{|c|c|c|c|c|}
\hline Sample $^{2}$ & WF & BF100 & BF130 & Coffee \\
\hline Specific volume (mL/g) & $6.15 \pm 0.73^{\mathrm{a}}$ & $5.98 \pm 0.47^{\mathrm{a}}$ & $6.77 \pm 0.63^{a}$ & $6.49 \pm 0.49^{\mathrm{a}}$ \\
\hline Spread ratio & $0.90 \pm 0.07^{\mathrm{a}}$ & $0.92 \pm 0.05^{\mathrm{a}}$ & $1.00 \pm 0.04^{\mathrm{b}}$ & $1.03 \pm 0.07^{\mathrm{b}}$ \\
\hline \multicolumn{5}{|l|}{ Colour values } \\
\hline$L^{*}$ & $81.38 \pm 1.98^{c}$ & $70.82 \pm 1.85^{b}$ & $69.10 \pm 0.86^{\mathrm{b}}$ & $52.58 \pm 1.86^{\mathrm{a}}$ \\
\hline$a^{*}$ & $0.39 \pm 0.13^{\mathrm{a}}$ & $1.93 \pm 0.15^{\mathrm{b}}$ & $1.71 \pm 0.14^{\mathrm{b}}$ & $7.78 \pm 0.33^{\mathrm{c}}$ \\
\hline$b^{*}$ & $16.59 \pm 0.40^{\mathrm{d}}$ & $15.70 \pm 0.41^{\mathrm{c}}$ & $14.96 \pm 0.64^{\mathrm{b}}$ & $7.78 \pm 0.33^{\mathrm{a}}$ \\
\hline Hue angle $\left(h^{\circ}\right)$ & $88.65 \pm 0.52^{\mathrm{c}}$ & $82.99 \pm 0.66^{\mathrm{b}}$ & $83.47 \pm 0.69^{b}$ & $45 \pm 1.98^{\mathrm{a}}$ \\
\hline $\operatorname{Chroma}^{*}\left(C^{*}\right)$ & $16.60 \pm 0.46^{\mathrm{c}}$ & $15.82 \pm 0.47^{\mathrm{bc}}$ & $15.06 \pm 0.73^{\mathrm{b}}$ & $11.01 \pm 0.38^{\mathrm{a}}$ \\
\hline \multicolumn{5}{|l|}{ Texture analysis } \\
\hline Hardness (g) & $529.67 \pm 5.63^{\mathrm{a}}$ & $775.00 \pm 83.97^{b}$ & $5518.00 \pm 154.35^{\mathrm{a}}$ & $615.17 \pm 124.59^{\mathrm{a}}$ \\
\hline Cohesiveness & $0.86 \pm 0.04^{\mathrm{b}}$ & $0.81 \pm 0.16^{\mathrm{a}}$ & $0.82 \pm 0.01^{\mathrm{a}}$ & $0.81 \pm 0.03^{\mathrm{a}}$ \\
\hline Springiness (mm) & $9.67 \pm 0.10^{\mathrm{a}}$ & $9.55 \pm 0.05^{\mathrm{a}}$ & $9.67 \pm 0.05^{\mathrm{a}}$ & $9.60 \pm 0.15^{\mathrm{a}}$ \\
\hline Adhesiveness (mJ) & $0.20 \pm 0.11^{\mathrm{a}}$ & $0.13 \pm 0.05^{\mathrm{a}}$ & $0.10 \pm 0.00^{\mathrm{a}}$ & $0.12 \pm 0.04^{\mathrm{a}}$ \\
\hline
\end{tabular}

1 Physical properties stated in table where value represented the mean \pm SD, where $n=9$

2 WF: Control, $100 \%$ Wheat flour only

BF100: 85\% Wheat flour, 15\% Banana Flour and 100\% water

BF130: $85 \%$ Wheat flour, 15\% Banana Flour and 130\% water

Coffee: $85 \%$ Wheat flour, 15\% Banana Flour, 130\% water and 2.5\% coffee

a-d Same superscripts in the same row indicated no significant differences ( $>0.05)$ among samples

BF100. With BF incorporated into the dough, it can be expected that there was an increase in starch and a slight decrease in gluten since BF contains high carbohydrate and low protein which affects the rheological properties of the dough (Onwuka, 2015; Bakare et al., 2017). It is possible that the increase in water which is needed to fully hydrate the starch present contributed to the gelatinisation reaction and hence the increase of the viscous-flow of the CSB dough (Dogan et al., 2010). The higher viscous flow of dough and lower extensibility possibly resulted in a higher spread ratio (Balestra, 2009).

Results of TPA shows that BF100 had a relatively hard texture whilst on the other hand, BFCoffee and BF130 were tested to be softer $(\mathrm{P}<0.05)$ and was comparable to WF. The hardness represents the peak force during the first cycle of the compression or the simulation of the teeth's first bite onto the surface of the CSB (Texture Technologies Corp 2014). Our preliminary study on CSB with $15 \% \mathrm{BF}$ showed an increase in TDF (unpublished) and past research reported that BF contained more dietary fibre and total starch (Juarez-Ambriz et al., 2008; Rodriguez-Ambriz et al., 2008; Menezes et al., 2011; Agama-Acevedo et al., 2012) and therefore would have higher WHC (Zhang et al., 2005; Rodríguez-Ambriz et al., 2008; Noor Aziah et al., 2012; Yangilar, 2015). Therefore, the harder texture in BF100 (775.00 $\pm 83.97 \mathrm{~g})$ could be expected due to more solid components, incomplete gelatinisation of starch, less gluten matrix, and less expansion of gas cells. Similar results showing increased hardness were found in steamed bread with high fibre ingredients, low gluten grains, high amylose maize starch (Lin et al., 2012;
Wang et al., 2015; Wang et al., 2017) and in bread with BF (Noor Aziah et al., 2012). A study on the effect of bran on flour dough revealed that addition of bran caused a re-distribution of water in the flour and bran dough system which promotes partial dehydration of gluten, trans- conformational change in dough structure which leads to poor quality of bread containing added bran (Bock et al., 2013). In another study by Steglich et al. (2014) on the effects of raw materials on the microstructure and water distribution of cooked pasta, light microscopy showed that large fibre particles partly acted as barriers against water migration and protected starch granules from swelling. In this study, the additional water added in BF130 and BFCoffee could have assisted in hydrating gliadin and glutenin proteins as well as decrease the competition between gluten proteins for water, enabling the starch molecules to be fully hydrated (Haegens, 2006) which led to the formation of a softer dough. In a study on variations in dough water absorption on texture softness, results showed that 3-4\% more water softened the steamed breadcrumb (Rubenthaler et al., 1990). Cai et al. (2015) also showed hydration of bran improved the bread loaf volume with lower crumb firmness. It is possible that the gelatinisation process during steaming absorbed water into banana starch granules in the presence of adequate heat of above $68^{\circ} \mathrm{C}$ (da Mota et al., 2000; Bezerra et al., 2013) expanding the starch granules and improving the texture of the BF-CSB substituted with 15\% BF. During this reaction, a series of processes at the molecular scale such as swelling, melting, disruption of starch granules will occur. Hence, the partially swollen granules will then be stretched into elongated forms in order for the expansion of gas cells to take place affecting the quality 
of the product (Zhou and Therdthai, 2007). As for the BFCoffee, the organic acids, chlorogenic acids, aliphatic acids and quinic acids likely to be present in coffee (Farah, 2012) could also have lowered the $\mathrm{pH}$ of the dough, enabling the yeast and enzymes in the dough to become more active thus softening the gluten in the dough (Haegen, 2006).

Cohesiveness is a measure of the extent to which material can be deformed before it ruptures (Szczesniak 2002). It is also an indication of the chewiness of the food (Meilgaard, 1999) and is a good quality parameter in CSB (Hou and Popper, 2006). WF had the highest cohesiveness and was significantly different $(p<0.05)$ from all other BF samples. This can be expected as WF contains the highest proportion of gluten. The glutenin in gluten provides the elasticity while gliadin provides the plasticity and hence these characteristics in WF makes it more difficult to rupture when a force is applied to it (Brown, 2008). The decreased cohesiveness with the incorporation of BF was also possibly due to a denser structure of the CSB (Noor Aziah et al., 2012; Wang et al., 2017). In comparison to BF100, the addition of extra $30 \%$ water did not significantly affect the cohesiveness of the samples. Springiness or elasticity (Alvarez et al., 2002) refers to the rate at which a deformed material goes back to its un-deformed condition after the deforming force is removed (Szczesniak, 2002). According to Hou and Popper (2006), a good quality CSB should be elastic. It was expected that bread with higher gluten content will be more elastic (Brown, 2006). The results, however, show that there was no significant difference among all the samples. Adhesion means the force required to remove the material that adheres to the mouth (generally the palate) during the normal eating process (Szczesniak, 2002). Hou and Popper (2006) proposed that a good quality CSB should not be sticky to the palate when eating. Adhesiveness of a flour-based product may be affected by the amylose content in flours. A study by Guo et al. (2003) reported that noodle samples with highest amylose content had the lowest adhesiveness and vice versa. In comparison to wheat flour which has approximately $25 \%$ amylose, various cultivars of $\mathrm{BF}$ contain higher amylose content in the range of 25-31.2\% (Hegenbart, 1996). Although WF did show higher adhesiveness in comparison to $\mathrm{BF}$ samples, there were, however, no significant differences $(p>0.05)$ in the adhesion among the samples due to the high standard deviation in the results. Further research may be needed to determine the optimum water level that would produce a quality CSB with the desired texture characteristics.

\subsection{Consumer acceptability}

Hedonic ratings for the sensory attributes of the CSB samples is shown in Table 3. The acceptability for the appearance of CSB was different among formulations $(p<0.05)$. WF had the highest scores $(7.19 \pm 1.36)$ $(p<0.05)$ probably due to its light colour and smooth texture. BF100, on the other hand, had the lowest score $(5.87 \pm 1.49) \quad(p<0.05)$ due to its unfavourable rough surface texture and grey hue with spots of banana seeds. Although BF130 was not significantly different in colour to BF100, its smoother texture appearance significantly $(p<0.05)$ increased consumers favourability towards it. Similarly, BFCoffee had a higher liking score compared to B100 as they could accept the dark brown colour attributing it to the added coffee flavour. Colour has an important role in affecting expectations from consumers (Sung, 2014) and in this case the brown coffee colour has successfully masked the undesirable grey BF colour and spots from banana seeds. For aroma, results show that consumers preferred the natural wheat aroma in $\mathrm{WF}$

Table 3. Consumer acceptability scores ${ }^{1}$ for each sensory attribute in different CSB samples

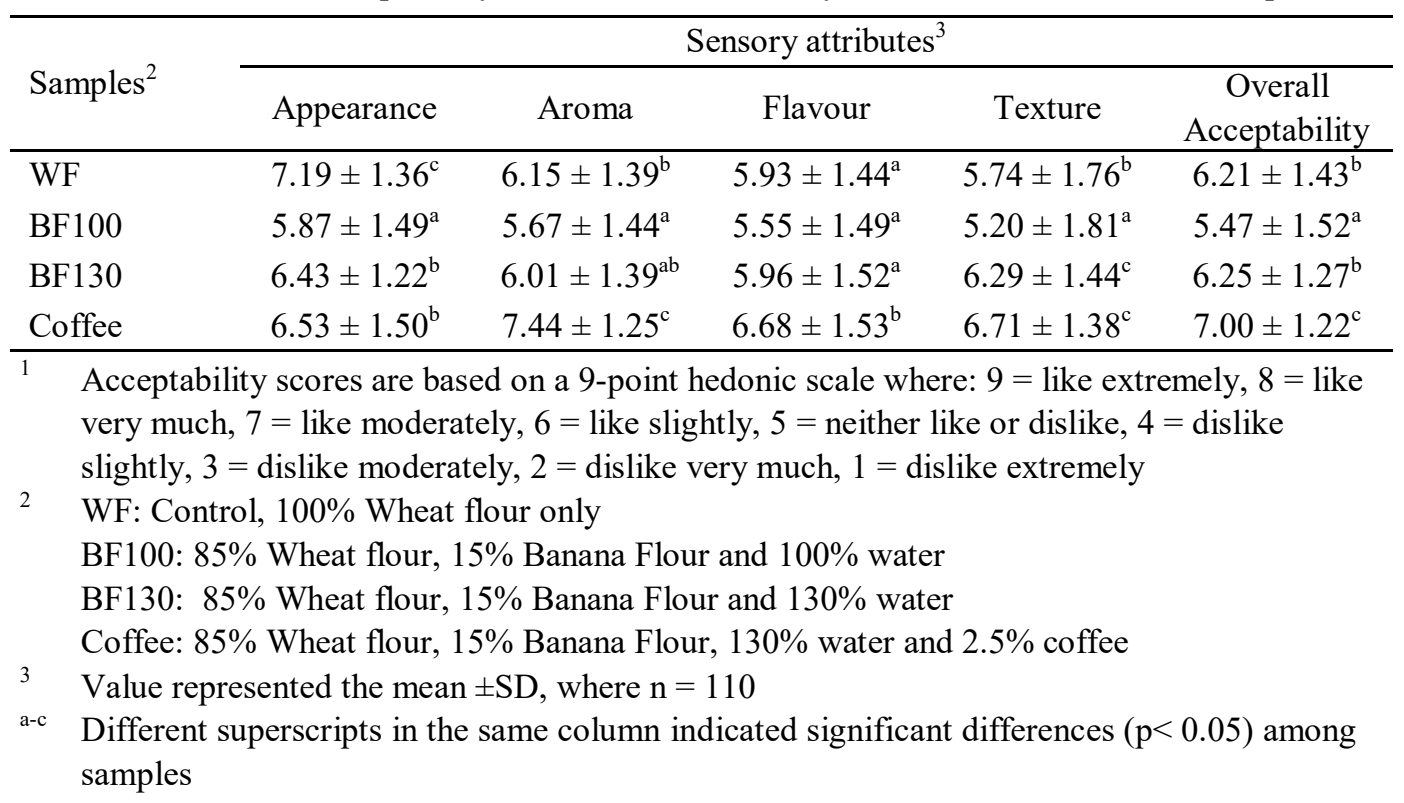


over the aroma of green banana flour in BF100. Liking for BF130's aroma was comparable to WF as the presence of water in BF130 could have diluted and weakened the strong banana aroma. Overall, BFCoffee's aroma was most favoured (hedonic score $7.44 \pm 1.25$ ) in comparison to the other BF samples $(\mathrm{p}<0.05)$ consisting the same amount of $\mathrm{BF}$ and even surpassing WF (6.15 \pm 1.39$)$. The presence of fragrant coffee volatile compounds (Farah, 2012) in the CSB had improved the aroma. Similar results were obtained for flavour whereby consumers liked BFCoffee's flavour most $(6.68 \pm 1.53)$ $(\mathrm{p}<0.05)$ compared to all the other samples. Coffee flavour compounds such as chlorogenic acids, caffeine and trigonelline (Farah, 2012) and the interaction between smell and taste (Martin, 2013) may have contributed to the desirable outcome. The flavour acceptance of WF, BF100 and BF130 CSB were not significantly different as the basic ingredients affecting taste such as the amount of sugar added were similar for all samples. Consumers slightly liked the texture of BFCoffee and BF130 (6.71 $\pm 1.38,6.29 \pm 1.44)$ while BF100 had the lowest hedonic score $(5.20 \pm 1.81)$. The hardness of BF100 may have affected the consumer acceptability whilst on the other hand, BFCoffee and BF130 was relatively soft and smooth. Although BF130 appeared to have a rougher surface texture, consumers favoured BF130's texture over WF CSB. Consumers may not have penalised the rough surface parameter as it is possible that consumers may have a higher acceptability towards BF130 due to their knowledge that it is a fibre enriched product which gives certain health benefits (Ares et al., 2008). Hence, these criteria may have been important in affecting the judgement of consumers. Based on overall acceptability, BFCoffee $(7.00 \pm 1.22)$ was moderately liked and was significantly most favoured $(\mathrm{P}<0.05)$. This was reflected in the high score ratings for aroma, flavour and texture attributes mentioned above. BF130 and WF had the second

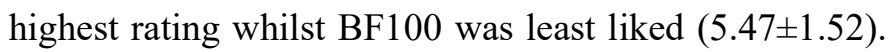
The addition of $30 \%$ water into CSB incorporated with BF had successfully increased its hedonic acceptability among consumers due to improvements in appearance and texture. Furthermore, it obtained an overall acceptability comparable to WF. Besides, the addition of coffee flavour significantly increased the hedonic ratings of CSB incorporated with BF in most sensory attributes.

Results of the preference ranking test in Table 4 also shows that BFCofffee was significantly preferred $(p<0.05)$ among the samples with BF100 being least preferred. These results correlated to that of the overall acceptability in the hedonic test. In comparison to another study by Bakare et al. (2017) on bread made with pre-treated banana flour to prevent negative browning effect, results showed that the control which consisted of wheat flour still had better scores for appearance, texture and taste despite the pre-treatments on the BF. In comparison, this study shows that the brown colour of coffee was a simple yet effective strategy to successfully cover the undesirable colour and aroma of plain BF-CSB.

Table 4. Preference ranking of different CSB samples

\begin{tabular}{lcc}
\multicolumn{1}{c}{ Sample } & Mean Rank & Rank Order $^{1}$ \\
\hline WF & $2.71^{\mathrm{cb}}$ & 3 \\
BF100 & $3.07^{\mathrm{c}}$ & 4 \\
BF130 & $2.40^{\mathrm{b}}$ & 2 \\
Coffee & $1.82^{\mathrm{a}}$ & 1 \\
\hline
\end{tabular}

Order of preference $(1=$ most preferred, $2=$ moderately preferred, $3=$ less preferred, $4=$ least preferred)

$2 \mathrm{WF}=$ Control WF CSB with no extra addition of water $\mathrm{BF} 100=$ Control BF CSB with no extra addition of water $\mathrm{BF} 130=\mathrm{BF}$ CSB with extra addition of $30 \%$ water Coffee $=$ BF CSB with extra addition of $30 \%$ water and coffee flavour

${ }^{a-c}$ Different superscripts in the same column indicated significant differences $(p<0.05)$ among samples

\section{Conclusion}

In conclusion, the addition of extra water improved the textural properties and appearance of BF-CSB. Besides, the use of a natural colouring/flavouring to mask the unfavourable colour of BF-CSB has increased the consumer acceptability of the CSB. In addition, consumers also favoured the coffee flavour and aroma in coffee flavoured BF-CSB as compared to a normal plain CSB. Hence, with further improvements on the sensory properties of the CSB, there is potential that the CSB incorporated with $\mathrm{BF}$ can be introduced into the food industry successfully. Similar re-formulations on other food products nutritionally enhanced with banana flour may draw favourable consumer acceptability to these functional foods.

\section{Conflict of Interest}

The authors declare that there are no conflicts of interest.

\section{Acknowledgments}

We would like to acknowledge Ms. Wu Ying Wen for the preliminary studies of this work and Chef Loke Hoi Weng from UCSI University, Kuala Lumpur, Malaysia for his guidance and advice in the formulation of Chinese Steamed Bread.

\section{References}

Ahmed, J., Shivhare, U.S. and Raghavan, G.S.V. (2000). 
Rheological characteristics and kinetics of colour degradation of green chili puree. Journal of Food Engineering, 44, 239-244. https://doi.org/10.1016/ S0260-8774(00)00034-0

American Association of Cereal Chemists (AACC) (2000). Guidelines for Measurement of Volume by Rapeseed Displacement (Method 10-05-01). Minnesota, St. Paul, USA: AACC International.

Agama-Acevedo, E, Islas-Hernández, J.J., PachecoVargas, G., Osorio-Díaz, P. and Bello-Pérez, L.A. (2012). Starch Digestibility and Glycemic Index of Cookies Partially Substituted with Unripe Banana Flour. LWT - Food Science and Technology, 46(1), 177-182. https://doi.org/10.1016/j.lwt.2011.10.010

Almanza-Benitez, S., Osorio-Díaz, P., MéndezMontealvo, P., Islas-Hernández, J.J. and Bello-Perez, L.A. (2015). Addition of Acid-Treated Unripe Plantain Flour Modified the Starch Digestibility, Indigestible Carbohydrate Content and Antioxidant Capacity of Semolina Spaghetti. LWT - Food Science and Technology, 62(2), 1127-1133. https:// doi.org/10.1016/j.lwt.2015.02.031

Alvarez, M., Canet, W. and López, M. (2002). Influence of deformation rate and degree of compression on textural parameters of potato and apple tissues in texture profile analysis. European Food Research Technology, 215(1), 13 - 20. https://doi.org/10.1007/ s00217-002-0515-0

Alves dos Santos, L.A., Lorenzo, J.M., Goncalves, C.A.A., Alves dos Santos, B., Heck, R.T., Cichoski, A.J. and Campagnol, P.C.B. (2016). Production of Healthier Bologna Type Sausages Using Pork Skin and Green Banana Flour as a Fat Replacers. Meat Science, 121, 73-78. https://doi.org/10.1016/ j.meatsci.2016.06.001

Ares, G., Gimenez, A. and Gambaro, A. (2008). Influence of nutritional knowledge on perceived healthiness and willingness to try functional foods. Appetite, 51, 663-668. https://doi.org/10.1016/ j.appet.2008.05.061

Bakare, A.H., Ogunbowale, O.D., Adegunwa, M.O. and Olusanya, J.O. (2017). Effects of Pretreatments of Banana (Musa AAA, Omini) on the Composition, Rheological Properties, and Baking Quality of Its Flour and Composite Blends with Wheat Flour. Food Science and Nutrition, 5(2), 182-196. https:// doi.org/10.1002/fsn3.378

Balestra, F. (2009). Empirical and fundamental mechanical tests in the evaluation of dough and bread rheological properties. Italy: Di Bologna University, $\mathrm{PhD}$ Thesis.

Bezerra, C.V., Amante, E.R., de Oliveira, D.C.,
Rodrigues, A.M.C. and Meller da Silva, L.H. (2013). Green Banana (Musa Cavendishii) Flour Obtained in Spouted Bed - Effect of Drying on PhysicoChemical, Functional and Morphological Characteristics of the Starch. Industrial Crops and Products, 41(1), 241-249. https://doi.org/10.1016/ j.indcrop.2012.04.035

Bock, J.E., Connelly, R.K. and Damodaran, S. (2013). Impact of Bran Addition on Water Properties and Gluten Secondary Structure in Wheat Flour Doughs Studied by Attenuated Total Reflectance Fourier Transform Infrared Spectroscopy. Cereal Chemistry, 90(4), 377-386. https://doi.org/10.1094/CCHEM-0113-0008-FI

Bourne, M.C. (2002). Food Texture and Viscosity: Concept and Measurement. $2^{\text {nd }}$ ed., p. 9-148. UK: Academic Press. https://doi.org/10.1016/B978012119062-0/50001-2

Brown, A. (2008). Understanding Food: Principles and Preparation. $3^{\text {rd }}$ ed., p. 387. Canada: Thomson Wadsworth.

Cai, L., Choi, L., Park, C.S. and Baik, B.K. (2015). Bran hydration and physical treatments improve the breadmaking quality of whole grain wheat flour. Cereal Chemistry, 92(6), 557-564. https://doi.org/10.1094/ CCHEM-04-15-0064-R

Chong, L.C. and Noor Aziah, A.A. (2008). Influence of Partial Substitution of Wheat Flour with Banana (Musa Paradisiaca Var. Awak) Flour on the PhysicoChemical and Sensory Characteristics of Doughnuts. International Food Research Journal, 15(2), 119124.

Choo, C.L. and Noor Aziah, A.A. (2010). Effects of Banana Flour and $\beta$-Glucan on the Nutritional and Sensory Evaluation of Noodles. Food Chemistry, 119(1), 34-40. https://doi.org/10.1016/ j.foodchem.2009.05.004

da Mota, V.R., Lajolo, F.M., Cordenunsi, B.R. and Ciacco, C. (2000). Composition and Functional Properties of Banana Flour from Different Varieties. Starch - Stärke, 52(2-3), 63-68. https:// doi.org/10.1002/(SICI)1521-379X(200004) 52:2/3<63::AID-STAR63>3.0.CO;2-V

Dadzie, B.K. and Orchard, J.E. (1997). Routine Post Harvest Screening of Banana/Plantain Hybrids: Criteria and Methods. Rome, Italy: INIBAP Technical Guidelines 2. International Plant Genetic Resources Institute, France: International Network for the Improvement of Banana and Plantain, Montpellier, Wageningen, The Netherlands: ACPEU Technical Centre for Agricultural and Rural Cooperation, 
Dogan, I.S., Yildiz, O. and Tasan, B. (2010). Spread and Microwave Oven Baking Test for Bread Making Quality. International Journal of Agriculture and Biology, 12(5), 697-700.

Farah, A. (2012). Coffee Constituents. In Chu, Y.F. (Ed.). Coffee: Emerging Health Effects and Disease Prevention, p. 27 - 28. Iowa: John Wiley and Sons, Inc. https://doi.org/10.1002/9781119949893.ch2

Gisslen, W. (2013). Professional Baking. $6^{\text {th }}$ ed. New Jersey: John Wiley and Sons, Inc.

Guo, G., Jackson, D.S., Graybosch, R.A. and Parkhurst, A.M. (2003). Asian Salted Noodle Quality: Impact of Amylose Content Adjustments Using Waxy Wheat Flour. Cereal Chemistry, 80(4), 437-445. https://doi.org/10.1094/CCHEM.2003.80.4.437

Haegens, N. (2006). Mixing, dough making, and dough makeup. In Hui, Y.H. (Eds.). Bakery Products: Science and Technology, p. 245 - 248. United States of America: Blackwell Publishing. https:// doi.org/10.1002/9780470277553.ch13

Hegenbart, S. (1996). Understanding Starch Functionality. Retrieved on April 7, 2015 from website: <http://www.foodproductdesign.com/ articles/1996/01/understanding-starchfunctionality.aspx $>$.

Hoseney, R.C., Hsu, K.H. and Junge, R.C. (1979). A simple spread test to measure the rheological properties of fermenting dough. Cereal Chemistry, 56(3), $141-143$.

Hou, G.G. and Popper, L. (2006). Chinese steamed bread. In Popper, L., Schäfer, W. and Freund, W. (Eds.). Future of flour - A compendium of flour improvement, p. 309-318. Germany: Agrimedia $\mathrm{GmbH}$ and Co.

Jha, S.N. (2010). Colour Measurements and Modeling. In Jha, S. (Ed.) Nondestructive Evaluation of Food Quality, p. 29. Berlin: Springer. https:// doi.org/10.1007/978-3-642-15796-7_2

Jirukkakul, N. (2016). The Study of Edible Film Production from Unriped Banana Flour and Riped Banana Puree. International Food Research Journal, 23(1), 95-101.

Juarez-Garcia, E., Agama-Acevedo, E., Sayago-Ayerdi, S.G., Rodriguez-Ambriz, S.L. and Bello-Perez, L.A. (2006). Composition, Digestibility and Application in Breadmaking of Banana Flour. Plant Foods for Human Nutrition, 61(3), 131-137. https:// doi.org/10.1007/s11130-006-0020-x

Kongolo, J.I., Da Silva, L.S., Wokadala, O.C., Du Plessis, B., Husselman, J., Ngcobo, Mduduzi E.K., Emmambux, N.M. and Daneel, M. (2017). Pasting, thermal, gel texture, resistant starch and colour properties of unripe banana flour from 10 desert banana varieties cultivated in South Africa. Journal of Food Measurement and Characterization, 11(3), 1056-1064. https://doi.org/10.1007/s11694-017-9481 $-\mathrm{X}$

Lai, J.Y. (2009). Effect of pumpkin (Cucurbita maxima) flour supplementation on the physical, chemical and sensory properties of wheat bread. Malaysia: UCSI University, BSc. Dissertation.

Lau, T.C., Chan, M.W., Tan, H.P. and Kwek, C.L. (2012). Functional food: A growing trend among the health conscious. Asian Social Science, 9(1), 198208. https://doi.org/10.5539/ass.v9n1p198

Lin, S.Y., Chen, H.H., Lu, S. and Andwang, P.C. (2012). Effects of blending of wheat flour with barley flour on dough and steamed bread properties. Journal of Texture Studies, 43, 438-444. https:// doi.org/10.1111/j.1745-4603.2012.00352.x

Martin, G.N. (2013). The Neuropsychology of Smell and Taste, p. 149. London: Psychology Press.

Meilgaard, M., Cuville, G.V. and Carr, T.B. (1999). Sensory Evaluation Techniques, p. 10, 182-183. New York: CRC Press. https:// doi.org/10.1201/9781439832271

Menezes, E.W., Tadini, C.C., Tribess, T.B., Zuleta, A., Binaghi, J., Pak, N. and Vera, G. (2011). Chemical Composition and Nutritional Value of Unripe Banana Flour (Musa Acuminata, Var. Nanicão). Plant Foods for Human Nutrition, 66(3), 231-37. https://doi.org/10.1007/s11130-011-0238-0

Mohammed Zafar, I.M., Bhatawale, S.P, Mehrajfatema, Z.M., Mirza, R.S. and Mohammad, U.I. (2012). Effect of Unripe Banana Flour Incorporation in Rice Papad and Resistance Starch Content. Journal of Food Processing and Technology, 3(8), 169. https:// doi.org/10.4172/2157-7110.1000169

Ng, K., Bhaduri, S., Ghatak, R. and Navder, K.P. (2012). Effect of Banana Flour on the Physical, Textural and Sensory Characteristics of Gluten-Free Muffins. Journal of the Academy of Nutrition and Dietetics, $112 \quad$ (9), A58. https://doi.org/10.1016/ j.jand.2012.06.211

Noor Aziah, A.A., Ho, L.H., Noor Shazliana, A.A. and Rajeev Bhat. (2012). Quality Evaluation of Steamed Wheat Bread Substituted with Green Banana Flour. International Food Research Journal, 19(3), 86976.

Onwuka, G.I. (2015). Comparative Evaluation of Proximate Composition and Functional Properties of Two Varieties of Cooking Banana. Journal of Environmental Science, Toxicology and Food Technology, 9(1), 01-04. 
Ovando-Martinez, M., Sáyago-Ayerdi, S., AgamaAcevedo, E., Goñi, I. and Bello-Pérez, L.A. (2009). Unripe Banana Flour as an Ingredient to Increase the Undigestible Carbohydrates of Pasta. Food Chemistry, 113(1), 121-126. https://doi.org/10.1016/ j.foodchem.2008.07.035

Pragati, S., Genitha, I. and Ravish, K. (2014). Comparative Study of Ripe and Unripe Banana Flour during Storage. Journal of Food Processing and Technology, 5(11), 384

Prasad Rao, R.S., Manohar, R.S. and Muralikrishn, G. (2007). Functional properties of water-soluble nonstarch polysaccharides from rice and ragi: Effect on dough characteristics and baking quality. Food Science and Technology, 40, 1678-1686. https:// doi.org/10.1016/j.lwt.2006.12.014

Raju, P.S. and Bawa, A.S. (2006). Food Additives in Fruit Processing. In Hui, Y.H. (Ed.). Handbook of Fruits and Fruit Processing, p. 158 - 159. Iowa: Blackwell Publishing. doi.org/10.1002/9780470277737.ch9

Ritthiruangdej, P., Parnbankled, S., Donchedee, S. and Wongsagonsup, R. (2011). Physical, Chemical, Textural and Sensory Properties of Dried Wheat Noodles Supplemented with Unripe Banana Flour. Kasetsart Journal - Natural Science, 45(3), 500-509.

Rodríguez-Ambriz, S.L., Islas-Hernández, J.J., AgamaAcevedo, E., Tovar, J. and Bello-Pérez, L.A. (2008). Characterization of a Fibre-Rich Powder Prepared by Liquefaction of Unripe Banana Flour. Food Chemistry, 107(4), 1515-1521. https:// doi.org/10.1016/j.foodchem.2007.10.007

Rubenthaler, G.L., Huang, M.L. and Pomeranz, Y. (1990). Steamed Bread. Chinese Steamed Bread Formulation and Interactions. Cereal Chemistry, 67 (5), 471-75.

Sarda, F.A.H., Giuntini, E.B., Gomez, M.L., Lui, M.C.Y., Negrini, J.A.E., Tadini, C.C., Lajolo, F.M. and Menezes, E.W. (2016). Impact of Resistant Starch from Unripe Banana Flour on Hunger, Satiety, and Glucose Homeostasis in Healthy Volunteers. Journal of Functional Foods, 24, 63-74. https://doi.org/10.1016/j.jff.2016.04.001

Saifullah, R., Abbas, F.N.A., Yeoh, Y.S. and Azhar, M.E. (2009). Utilization of Green Banana Flour as a Functional Ingredient in Yellow Noodle. International Food Research Journal, 16(3), 373379.

Siró, I., Kápolna, E., Kápolna, B. and Lugasi, A. (2008). Functional food: product development, marketing and consumer acceptance. Appetite, 51, 456-467. https://doi.org/10.1016/j.appet.2008.05.060
Sung, E.C. (2014). Sensory Evaluation. In Edelstein, S. (Eds.). Food Science: An Ecological Approach, p. 85, 90-100. Burlington: Jones and Bartlett Learning, LLC.

Steglich, T., Bernin, D., Röding, M., Nydén, N., Moldin, A., Topgaard, D. and Langton, M. (2014). Microstructure and water distribution of commercial pasta studied by microscopy and 3D magnetic resonance imaging. Food Research International, 62, 644-652. https://doi.org/10.1016/ j.foodres.2014.04.004

Swanson, R.B. (2004). Bakery: Yeast-leavened breads. In Smith, J.S. and Hui, Y.H. (Eds.). Food Processing: Principles and Applications, p. 188. Iowa: Blackwell Publishing. https:// doi.org/10.1002/9780470290118.ch9

Szczesniak, A.S. (2002). Texture is a Sensory Property. Food Quality and Preference, 13, 215 - 225. https:// doi.org/10.1016/S0950-3293(01)00039-8

Texture Technologies Corp. (2014). An Overview of Texture Profile Analysis (TPA). Retrieved on May 15, 2015 from Texture Technologies Website: http:// texturetechnologies.com/texture-profile-analysis/ texture-profile-analysis.php.

Tiboonbun, W., Sungsri-in, M. and Moongngarm, A. (2011). Effect of Replacement of Unripe Banana Flour for Rice Flour on Physical Properties and Resistant Starch Content of Rice Noodle. World Academy of Science, Engineering and Technology, 81, 608-611.

Tribess, T.B., Hernández-Uribe, J.P., MéndezMontealvo, M.G.C., Menezes, E.W., Bello-Perez, E.W. and Tadini, C.C. (2009). Thermal Properties and Resistant Starch Content of Green Banana Flour (Musa Cavendishii) Produced at Different Drying Conditions. LWT - Food Science and Technology, 42 (5). 1022-1025. https://doi.org/10.1016/ j.lwt.2008.12.017

Wang, Y., Zhang, M. and Mujumdar, A.S. (2012). Influence of Green Banana Flour Substitution for Cassava Starch on the Nutrition, Color, Texture and Sensory Quality in Two Types of Snacks. LWT Food Science and Technology, 47(1), 175-182. https://doi.org/10.1016/j.lwt.2011.12.011

Wang, S., Opassathavorn, A. and Zhu, F. (2015). Influence of quinoa flour on quality characteristics of cookie, bread and Chinese steamed bread. Journal of Texture Studies, 46, 281-292. https:// doi.org/10.1111/jtxs. 12128

Wang, S., Khamchanxana, P., Zhu, F., Zhu, C. and Pan, J. (2017). Textural and Sensory Attributes of Steamed Bread Fortified with High-Amylose Maize 
Starch. Journal of Texture Studies, 48(1), 3-8. https://doi.org/10.1111/jtxs.12208

Yangilar, F. (2015). Effects of Green Banana Flour on the Physical, Chemical and Sensory Properties of Ice Cream. Food Technology and Biotechnology, 53(3), 315-323.

Zhang, P., Whistler, R.L., Bemiller, J.N. and Hamaker, B.R. (2005). Banana Starch: Production, Physicochemical Properties, and Digestibility - A Review. Carbohydrate Polymers, 59(4), 443-458. https://doi.org/10.1016/j.carbpol.2004.10.014

Zhou, W.B. and Therdthai, N. (2007). Manufacturing of Bread and Bakery Products. In Hui, Y.H. (Ed.). Handbook of Food Products Manufacturing, p. 265. New Jersey: John Wiley and Sons. https:// doi.org/10.1002/9780470113554.ch14

Zhu, F. (2014). Influence of Ingredients and Chemical Components on the Quality of Chinese Steamed Bread. Food Chemistry, 163, 154-162. https:// doi.org/10.1016/j.foodchem.2014.04.067 